\title{
Binding of Pseudomonas cepacia to Normal Human Intestinal Mucin and Respiratory Mucin from Patients with Cystic Fibrosis
}

\author{
Umadevi S. Sajjan, Mary Corey, Mohamed A. Karmali, and Janet F. Forstner \\ Research Institute, Hospital for Sick Children, University of Toronto, Toronto, Ontario, M5G 1X8, Canada
}

\begin{abstract}
Although not as prevalent as Pseudomonas aeruginosa, Pseudomonas cepacia is another opportunistic pathogen which colonizes the lungs of at least some patients with cystic fibrosis. A subgroup of these patients exhibits the "cepacia syndrome", i.e., a rapid clinical deterioration and death within one year. To investigate potential early sites of bacterial attachment, we have measured the specific binding of $P$. cepacia isolates from cystic fibrosis (CF) sputa to both $\mathrm{CF}$ and non-CF mucins purified from respiratory and intestinal secretions, respectively. As shown in microtiter binding assays, clinical isolates from 19/22 patients were found to bind to both mucins, with the highest specific binding exhibited by isolates from eight patients, seven of whom later died with the cepacia syndrome. No differences were observed in the binding capacity of the two (CF versus non-CF) mucins. Binding was specific, saturable, and not influenced by tetramethylurea, a disruptor of hydrophobic associations. Individual sugars were ineffective as hapten inhibitors, as were several lectins. Mucins treated by reduction/alkylation or chloroform/methanol extraction showed enhanced bacterial binding, findings which were attributed to exposure of underlying binding sites. Deglycosylation procedures indicated that mucin receptors for $P$. cepacia include $\boldsymbol{N}$-acetylglucosamine and $\mathrm{N}$-acetylgalactosamine, probably linked together as part of core oligosaccharide structures. $P$. cepacia isolates also bound to buccal epithelial cells, and mucin partially inhibited the binding of those isolates of $\boldsymbol{P}$. cepacia that also had the ability to bind to mucin. We speculate that specific binding of $\boldsymbol{P}$. cepacia to secreted mucins may be an early step in the pathogenesis of the cepacia syndrome. (J. Clin. Invest. 1992. 89:648-656.) Key words: mucin adhesion • carbohydrate receptors $\bullet$ buccal epithelial cells $\bullet$ binding assays $\bullet$ mucin competition
\end{abstract}

\section{Introduction}

Pseudomonas cepacia, a well known plant pathogen, was first described as an opportunistic pathogen in cystic fibrosis (CF $)^{1}$

Preliminary reports of this work have appeared in abstract form (1990. Pediatr. Pulmonology. Suppl. 5:196A; and 1991. Glyconjugate J. 8:209).

Address correspondence to J. F. Forstner, M. D., Ph.D., The Hospital for Sick Children, 555 University Avenue, Room 3423, Toronto, Ontario M5G 1X8, Canada. 1991.

Received for publication 7 June 1991 and in revised form 11 October

1. Abbreviations used in this paper: $\mathrm{BEC}$, buccal epithelial cells; $\mathrm{CF}$, cystic fibrosis; dpm, disintegrations per minute; FEVI, forced expira-

J. Clin. Invest.

(c) The American Society for Clinical Investigation, Inc. 0021-9738/92/02/0648/09 \$2.00

Volume 89, February 1992, 648-656 patients in the early 1970 s (1). Unlike Pseudomonas aeruginosa, this organism infects a small percentage of CF patients. Over the last 20 years, however, the prevalence of $P$. cepacia infection in CF has gradually increased in some centers $(2,3)$. A recent survey at the Hospital for Sick Children, Toronto, suggested that approximately $40 \%$ of a total of $500 \mathrm{CF}$ patients are now colonized with this organism. The infection is believed to spread by nosocomial transmission $(4,5)$ but once acquired, the clinical course is quite variable. Some patients show no particular alteration in the course of their disease, some show a mildly accelerated decline, while others succumb to a rapid decline in pulmonary function with fever, elevation of erythrocyte sedimentation rate, leukocytosis, and resistance to antibiotic therapy, culminating in death within several months to a year. This rapid fatal deterioration has been called the "cepacia syndrome" $(2,6)$. Very little is known about the pathogenesis of this syndrome or the virulence factors responsible, although several potential virulence factors have been described for $P$. cepacia, including proteolytic, hemolytic, lipolytic, and saccharolytic activities $(7,8)$. Unfortunately, evidence that pulmonary pathology is a direct result of these factors is nonexistent or at best very weak.

Kuehn et al. (9) reported that both CF and non-CF P. cepacia isolates bind to respiratory epithelial cells, and suggested that polar pili on $P$. cepacia may play a role in adhesion and initiation of infection. In contrast, Saiman et al. (10) suggested that outer membrane proteins of $P$. cepacia mediate adhesion to respiratory cells. Krivan et al. (11) have demonstrated that selected CF and non-CF $P$. cepacia and $P$. aeruginosa isolates also bind in vitro to asialo glycolipids, with the specific receptor sequence in each case being $N$-acetylgalactosamine (GalNAc) $\beta$ 1,4 galactose (GAL).

Autopsy specimens of CF lung (12) and ferret lung (used in a CF model system) (13), have shown that respiratory pathogens in general tend to localize within luminal mucus secretions rather than adhere to cells. To our knowledge no reports of $P$. cepacia localization in CF lungs have been published.

In an effort to explore potentially important early events of $P$. cepacia infection in CF patients at the Hospital for Sick Children in Toronto, we undertook a study of the binding of $P$. cepacia isolates to purified human mucins. Our goals were to discover whether there was specific binding of $P$. cepacia to mucins, whether binding was different for non-CF intestinal mucin than for CF tracheobronchial mucin, and whether we could obtain information about the specific receptor structures on mucins involved in $P$. cepacia adhesion. In addition we explored the binding of $P$. cepacia isolates to buccal epithelial cells and the ability of mucins to interfere with this binding.

tory volume in $1 \mathrm{~s}$; Gal, galactose; GalNAc, $N$-acetylgalactosamine; GlcNAc, $N$-acetylglucosamine; SIM, small intestinal mucin; TBM, tracheobronchial mucin; TFMS, trifluoromethane sulfonic acid. 


\section{Methods}

\section{Bacterial strains and culture conditions}

From sputum cultures of 22 patients with cystic fibrosis, who were seen in the out-patient clinic or who were hospitalized for brief periods during 1986 to 1989,53 clinical isolates of $P$. cepacia were identified. Although these isolates were sent to the Center for Disease Control, Atlanta, Georgia, for ribotype analyses, the results are not yet available. Therefore precise strain differences (if any) amongst the isolates are unknown. Identification of $P$. cepacia in the Clinical Microbiology Laboratory was made on the basis of identification schema outlined by Gilardi (14), including colonial morphologies, odor, and Gram-negative staining of motile rod-shaped bacteria. In addition, isolates were catalase positive, weakly oxidase positive, did not ferment glucose, gave good growth on McConkey medium, were resistant to polymyxin B sulphate $(10 \mathrm{mg} / \mathrm{liter}$ ), gave positive glucose oxidation reaction (Hugh and Leifson medium) and positive growth in Simmon's citrate medium. Results of specific tests used to distinguish $P$. cepacia from closely related species in Pseudomonas RNA group II included negative arginine dihydrolase activity, positive hydrolysis of $O$-nitrophenyl$\beta$-D-galactopyranoside, and positive esculin hydrolysis (for most of the isolates). Each culture was suspended in sterile water, transferred onto brain heart infusion agar plates, grown for $36-48 \mathrm{~h}$ at $37^{\circ} \mathrm{C}$, and then maintained at $-70^{\circ} \mathrm{C}$ in vials containing $5 \%$ trisodium citrate in $40 \%$ glycerol.

In preparation for binding studies, bacteria were subcultured on brain heart infusion agar plates, grown for $36-48 \mathrm{~h}$, and single colonies inoculated into $10 \mathrm{ml}$ of trypticase soy broth (Difco Laboratories, Inc., Detroit, MI) supplemented with $0.1 \mathrm{mCi}$ of $\left[{ }^{3} \mathrm{H}\right]$ sodium acetate (ICN Biomedicals Inc., Costa Mesa, CA) (sp act $2.5 \mathrm{Ci} / \mathrm{mmol}$ ) or $\left[{ }^{35} \mathrm{~S}\right] \mathrm{L}$ methionine (New England Nuclear Research Products, Boston, MA) (sp act $800 \mathrm{Ci} / \mathrm{mmol}$ ). Bacteria were grown under aerobic conditions in an Orbit shaker (CanLab, Mississauga, Ontario, Canada) at $150 \mathrm{rpm}$ for $16-18 \mathrm{~h}$ at $37^{\circ} \mathrm{C}$. The broth was centrifuged at $10,000 \mathrm{~g}$ for $10 \mathrm{~min}$ at $4^{\circ} \mathrm{C}$, and the bacterial pellet washed three times with 20 vol of PBS pH 7.0 containing $0.1 \%$ BSA (fraction V, essentially globulin free; Sigma Chemical Co., St. Louis, MO). The pellet was resuspended in the same PBS-BSA solution to give a concentration suitable for subsequent binding assays $\left(0.1 \mathrm{OD}\right.$ at $650 \mathrm{~nm}$ was equal to $2.52 \times 10^{8} \mathrm{CFU} / \mathrm{ml}$ as determined by plating serially diluted bacteria).

\section{Patient data}

Selected information on each patient from whom isolates were obtained was entered routinely into the CF patient data registry at the Hospital for Sick Children. On the basis of several clinical parameters, including pulmonary function tests (FEV1, forced vital capacity, chest $\mathrm{x}$ ray, and weight and height for age, patients were placed into one of three groups at the time each isolate was obtained: i.e., advanced, moderate, or mild severity of illness. Follow up mortality data on each patient were maintained as part of the ongoing data registry at this hospital.

\section{Purification of mucins}

Tracheobronchial mucin (TBM) from combined sputa of CF patients, and small intestinal mucin (SIM) from ileal secretions of a nonCF patient were purified, and compositional assays for carbohydrate and amino acids were performed, as described in the accompanying paper (15).

\section{Modifications of intestinal mucin structure}

Reduction and alkylation. Mucin ( $377 \mu \mathrm{g}$ as protein or $3.7 \mathrm{mg}$ as dry wt) was mixed with DTT $(10 \mathrm{mM})$ in $0.05 \mathrm{M}$ Tris $\mathrm{HCl}$ buffer $\mathrm{pH} 8.6$ containing $1 \%$ SDS, boiled for $5 \mathrm{~min}$, cooled to room temperature, and alkylated with iodoacetamide $(20 \mathrm{mM})$ for $1 \mathrm{~h}$ at room temperature in the dark. Excess reagents were removed by dialysis for $24 \mathrm{~h}$ against six changes of distilled $\mathrm{H}_{2} \mathrm{O}$.

Delipidation. Five sequential chloroform:methanol extractions of mucin ( $20 \mathrm{mg}$ dry wt) were carried out by the method of Slomiany et al.
(16) to remove potential lipid contaminants. Extracts were pooled, concentrated by rotary flash evaporation, and redissolved in $100 \mu \mathrm{l}$ of chloroform:methanol $(2: 1 \mathrm{vol} / \mathrm{vol})$ for subsequent use in thin layer chromatography. The residual mucin was used in bacterial binding or hapten inhibition assays.

Desulfation. Mucin $(3.77 \mathrm{mg})$ was treated with $4 \mathrm{ml}$ of $0.05 \mathrm{M} \mathrm{HCl}$ in dry methanol at $37^{\circ} \mathrm{C}$ for $4 \mathrm{~h}$ as described by Slomiany et al. (17), neutralized with $1 \mathrm{M} \mathrm{NaOH}$, dialyzed against three changes of distilled $\mathrm{H}_{2} \mathrm{O}$, and concentrated by freeze drying. Mucin sulfate was measured by the method of Silvestri et al. (18) before and after methanolic- $\mathrm{HCl}$ treatment.

Deglycosylation. (a) Partial deglycosylation was accomplished by subjecting mucin $(27 \mathrm{mg})$ to two sequential treatments with trifluoromethane sulfonic acid (TFMS):anisole $(2: 1)$ for $2 \mathrm{~h}$ at $0^{\circ} \mathrm{C}$ as described by Edge et al. (19).

(b) Total deglycosylation was achieved by subjecting the partially deglycosylated mucin to "reverse" $\beta$-elimination as outlined by Gerken et al. (20). Briefly, this entailed the addition of $0.1 \mathrm{M}$ acetic acid to a solution of partly deglycosylated mucin $(6.4 \mathrm{mg}$ in $1 \mathrm{ml}$ of distilled $\mathrm{H}_{2} \mathrm{O}$ ) to bring the $\mathrm{pH}$ to 4.5 , incubation with sodium metaperiodate $(200 \mathrm{mM})$ at $4^{\circ} \mathrm{C}$ overnight in the dark, destruction of excess periodate by the addition of sodium iodide/sodium thiosulphate reagent ( $1: 1 \mathrm{vol} /$ vol $200 \mathrm{mM} \mathrm{NaI}$ and $800 \mathrm{mM} \mathrm{Na} \mathrm{S}_{2} \mathrm{O}_{3}$ ), and incubation for $12 \mathrm{~h}$ at $4^{\circ} \mathrm{C}$. The deglycosylated mucin was then dialyzed at $4^{\circ} \mathrm{C}$ against distilled $\mathrm{H}_{2} \mathrm{O}$ for $3 \mathrm{~d}$ and freeze dried.

Proteolytic digestion. Mucin $(3.7 \mathrm{mg}$ ) was incubated with $754 \mu \mathrm{g}$ of protease (type X1V, Sigma Chemical Co.) in PBS pH 7.2 for $24 \mathrm{~h}$ at $37^{\circ} \mathrm{C}$ as described earlier (21). PMSF $(2 \mathrm{mM})$ was then added and the mixture dialyzed for $24 \mathrm{~h}$ against distilled $\mathrm{H}_{2} \mathrm{O}$. No attempt was made to remove residual pronase from the retentate.

Periodate treatment. Sodium metaperiodate $(0-100 \mathrm{mM})$ was added to mucin-coated microtiter wells and incubated for $1 \mathrm{~h}$ at $37^{\circ} \mathrm{C}$. After washing the wells, standard bacterial binding assays were performed. More details of the procedure are provided in Results (Table IV).

\section{Bacterial binding to mucin}

Microtiter plate assays. Binding of $P$. cepacia to either SIM or TBM was performed in wells of polyvinyl microdilution plates as described in the accompanying paper (15) with a minor modification, namely, that throughout the assay PBS containing $0.1 \%$ BSA was used instead of PBS alone. This modification did not affect specific binding, it simply reduced background binding to BSA. Specific binding to mucin was calculated in some experiments by subtracting the disintegrations per minute (dpm) of BSA-bound bacteria from the dpm of mucin-bound bacteria, and the resulting value then converted to $\mathrm{CFU} / \mu \mathrm{g}$ mucin. In other experiments specificity of binding to mucin was expressed as a binding ratio $R$, which is the dpm bound to mucin divided by dpm bound to BSA. In hapten inhibition experiments the $R$ value for binding of controls (no hapten) was used as a reference ( $0 \%$ inhibition) to facilitate comparisons with samples exposed to haptens.

Slot-blot binding assays. Native or modified mucins (50-500 ng as protein) were slot-blotted onto $0.45-\mu \mathrm{m}$ nitrocellulose membranes (Bio-Rad Laboratories, Richmond, CA) in a slot-blot system manifold II (Schleicher and Schuell Inc., Keene, NH), washed, and blocked with $3 \%$ gelatin for $1 \mathrm{~h}$ at $37^{\circ} \mathrm{C}$. The membrane was then incubated with ${ }^{35}$ S-labelled P. cepacia $\left(2-3 \times 10^{9} \mathrm{CFU} / \mathrm{ml}\right)$ in PBS-BSA pH 7.0 for $1 \mathrm{~h}$ at $37^{\circ} \mathrm{C}$. After washing, the membranes were dried, incubated for 5 min in rapid autofluor enhancer (New England Nuclear, Boston, MA) and exposed to X-OMAT AR film (Eastman Kodak, Rochester, NY) for 4-5 d. Intensity of slots was judged visually and by scanning densitometry by the use of a laser (Ultrascan XL; Pharmacia LKB, Uppsala, Sweden).

Thin layer chromatography overlay assay. Chloroform:methanol extracts of mucin $(10 \mu \mathrm{l})$ as well as purified reference glycolipids (1-2 $\mu \mathrm{g})$ were separated by thin layer chromatography on silica gel using chloroform:methanol: $\mathrm{H}_{2} \mathrm{O}(60: 40: 9)(\mathrm{vol} / \mathrm{vol} / \mathrm{vol})$ as a solvent system. 
The glycolipid standards were kindly supplied by Dr. C. Lingwood, Division of Microbiology, Hospital for Sick Children, and included asialo and monosialo gangliotetraosyl ceramides, asialo and monosialo gangliotriosyl ceramides, globotetraosyl-, globotriosyl-, and lactosyl ceramides (asialo GM1, GM1, asialo GM2, GM2, Gb4, Gb3, and LC, respectively). The silica plates were either stained with Orcinol reagent (Sigma Chemical Co., St. Louis, MO) (22) and visualized, or blocked with $1 \%$ gelatin overnight at $37^{\circ} \mathrm{C}$, incubated with $10 \mathrm{ml}$ of ${ }^{35} \mathrm{~S}$-labelled P. cepacia $\left(3 \times 10^{9} \mathrm{CFU} / \mathrm{ml}\right)$ for $1 \mathrm{~h}$ at $37^{\circ} \mathrm{C}$, washed six times with PBS-BSA, air dried, and processed for autoradiography. The method was essentially the same as that described by Hansson et al. (23).

Hapten inhibition assay. Potential haptens were preincubated with ${ }^{3} \mathrm{H}$-labelled bacteria for $1 \mathrm{~h}$ at $37^{\circ} \mathrm{C}$, followed by measurement of bacterial binding to mucin by the microtiter binding assay protocol. Further details for specific experiments are given in figure legends or tables in Results. Individual carbohydrates used as haptens were obtained from Sigma Chemical Co. Lectins (Helix pomatia, wheat germ agglutinin, peanut agglutinin, and Ulex europaeus I) were purchased from Biocarb Chemicals, Lund, Sweden.

Buccal epithelial binding assay. Binding of ${ }^{3} \mathrm{H}-P$. cepacia to buccal epithelial cells (BEC) was determined by following the method of Doig et al. (24). To test the effect of mucin on P. cepacia binding to BEC, ${ }^{3} \mathrm{H}$-bacteria were first incubated with mucin $(25-200 \mu \mathrm{g} / \mathrm{ml})$ for $1 \mathrm{~h}$ at $37^{\circ} \mathrm{C}$, the mixture was then incubated with $\mathrm{BEC}$, and the assay was continued as usual.

\section{Statistical analysis}

Statistical comparisons of binding results, $R$ values, and pulmonary function tests (FEV1), were performed by Student's $t$ test using Statworks, Cricket Software, Philadelphia, PA.

Linear regressions of Langmuir isotherm plots were computed by Cricket graph, (Cricket Software) and the slopes for each isolate were then compared with each other by multiple linear regression analysis using SAS Statistical Software, Cary, NC.

\section{Results}

\section{Binding of $P$. cepacia to intestinal or respiratory mucin}

Initial binding experiments involved the incubation of a fixed concentration $\left(1.0-1.5 \times 10^{9} \mathrm{CFU} / \mathrm{ml}\right)$ of ${ }^{3} \mathrm{H}$-labelled $P$. cepacia for $1 \mathrm{~h}$ at $37^{\circ} \mathrm{C}$ in microtiter wells coated with either purified normal human SIM or CF TBM. Radioactivity (dpm) of bacteria bound to mucin was divided by dpm of bacteria bound to BSA-coated wells to generate a ratio, $R$, which reflects specificity of binding to mucin. $R$ values $>2.0$ were taken to indicate a preference of binding for mucin (25). In contrast to $P$. aeruginosa strains (15) seven of the eight isolates of $P$. cepacia exhibited preferential binding to mucin. No major differences in binding between the normal and CF mucins were observed (Table I).

Using two isolates that showed the greatest mucin binding values (PC 5 and 7), experiments were conducted to discover the optimum conditions of time (0.5-3 h), temperature (22$37^{\circ} \mathrm{C}$ ), and $\mathrm{pH}(5.8-7.5)$, for binding. The results (not shown) indicated that $1 \mathrm{~h}$ at $37^{\circ} \mathrm{C}$ and $\mathrm{pH} 7.0$ gave the best binding, and these conditions were therefore used in subsequent binding or binding/inhibition studies. For three isolates that were explored in detail (PC 5, 7, 24), specific binding depended upon bacterial concentration and exhibited saturation at a concentration of $\sim 4-5 \times 10^{9} \mathrm{CFU} / \mathrm{ml}$. Fig. $1 a$ shows a representative plot for one isolate (PC 7) and Fig. $1 b$ the derived Langmuir isotherm, which gave a linear regression line suggestive of a single type of noninteracting mucin receptors. Fig. 2 shows that the binding of PC 7 to intestinal mucin was $80-90 \%$ inhibitable
Table I. Binding of P. cepacia Isolate to Mucins

\begin{tabular}{llccr}
\hline Isolates & Mucin & $\begin{array}{c}\text { dpm bound } \\
\text { to BSA (a) }\end{array}$ & $\begin{array}{c}\text { dpm bound } \\
\text { to mucin (b) }\end{array}$ & $\begin{array}{c}R \text { value } \\
\text { (b/a) }\end{array}$ \\
\hline PC 1 & SIM & $70(69-73)$ & $218(170-254)$ & 3.1 \\
& TBM & $70(69-73)$ & $238(197-273)$ & 3.4 \\
PC 2 & SIM & $785(714-872)$ & $2849(2780-2902)$ & 3.6 \\
& TBM & $785(714-872)$ & $2506(2234-2644)$ & 3.2 \\
PC 3 & SIM & $71(61-78)$ & $285(264-297)$ & 4.0 \\
& TBM & $71(61-78)$ & $256(247-275)$ & 3.6 \\
PC 4 & SIM & $41(21-61)$ & $169(133-194)$ & 4.1 \\
& TBM & $41(21-61)$ & $167(152-185)$ & 4.1 \\
PC 5 & SIM & $96(94-99)$ & $801(770-850)$ & 8.3 \\
& TBM & $96(94-99)$ & $833(805-886)$ & 8.6 \\
PC 7 & SIM & $58(52-63)$ & $2820(2515-3035)$ & 48.3 \\
& TBM & $70(66-75)$ & $3515(3116-3710)$ & 50.2 \\
PC 18* & SIM & $35(29-42)$ & $43(35-51)$ & 1.2 \\
PC 24* & SIM & $27(22-36)$ & $640(557-703)$ & 23.7 \\
& & & & \\
\hline
\end{tabular}

${ }^{3} \mathrm{H}-P$. cepacia isolates $\left(1.0-1.5 \times 10^{9} \mathrm{CFU} / \mathrm{ml}\right)$ were tested for binding to microtiter wells coated with BSA (control), SIM, or TBM. $R$ values $>2.0$ were considered to reflect specific binding to mucin. Values of $\mathrm{dpm}$ are the average ( \pm total range obtained) of three independent binding experiments. ${ }^{*}$ Binding to TBM was not determined.

by preincubating the bacteria with either SIM or TBM solutions before carrying out standard microtiter binding assays. For the three isolates, Langmuir isotherms permitted calculation of values for $N$ (saturation of mucin sites expressed as $\mathrm{CFU} / \mu \mathrm{g}$ mucin) and $K$ (association constant expressed as $\mathrm{ml} /$ $\mu \mathrm{g}$ mucin) (Table II). Multiple linear regression analyses of the isotherms indicated that differences in binding values amongst the isolates were statistically significant. However, the $K$ and $N$ values were all within one order of magnitude, which likely reflects similarity of bacterial adhesins and common, but perhaps not identical, mucin receptors. In later experiments, which were designed to probe the identity of mucin receptors, we frequently used both isolates PC 5 and 7 (and in selected cases both mucins) to ensure that our findings would not be restricted to one strain-specific mechanism of mucin binding.

Hydrophobic interactions, which play an important role in $P$. aeruginosa binding to mucin or BSA (15), were not found to influence $P$. cepacia binding to mucin, as judged by the total lack of effect of tetramethyl urea $(0.05-0.4 \mathrm{M})$ upon the binding of either PC 5 or PC 7 to mucins (not shown). This result in addition to the unequivocal specificity of $P$. cepacia binding to mucin (versus BSA), made it unnecessary to resort to solutionphase assays as was done earlier for $P$. aeruginosa (15).

\section{Survey of clinical isolates}

From 22 patients with cystic fibrosis who visited the outpatient clinic or were hospitalized during 1986 to 1989 , there were 53 $P$. cepacia isolates obtained. The clinical data relevant to each patient at the time the isolate was obtained and the subsequent clinical course of each patient (up until December 31, 1990) were documented and stored in the CF Patient Data Registry at the Hospital for Sick Children. Each isolate (at a fixed bacterial concentration of $1.2 \times 10^{9} \mathrm{CFU} / \mathrm{ml}$ ) was tested for its capacity to bind to SIM. A disproportionately high number (fifteen) of nonbinding isolates came from a total of 5 patients, 2 of whom later produced binding isolates during the third year of the 

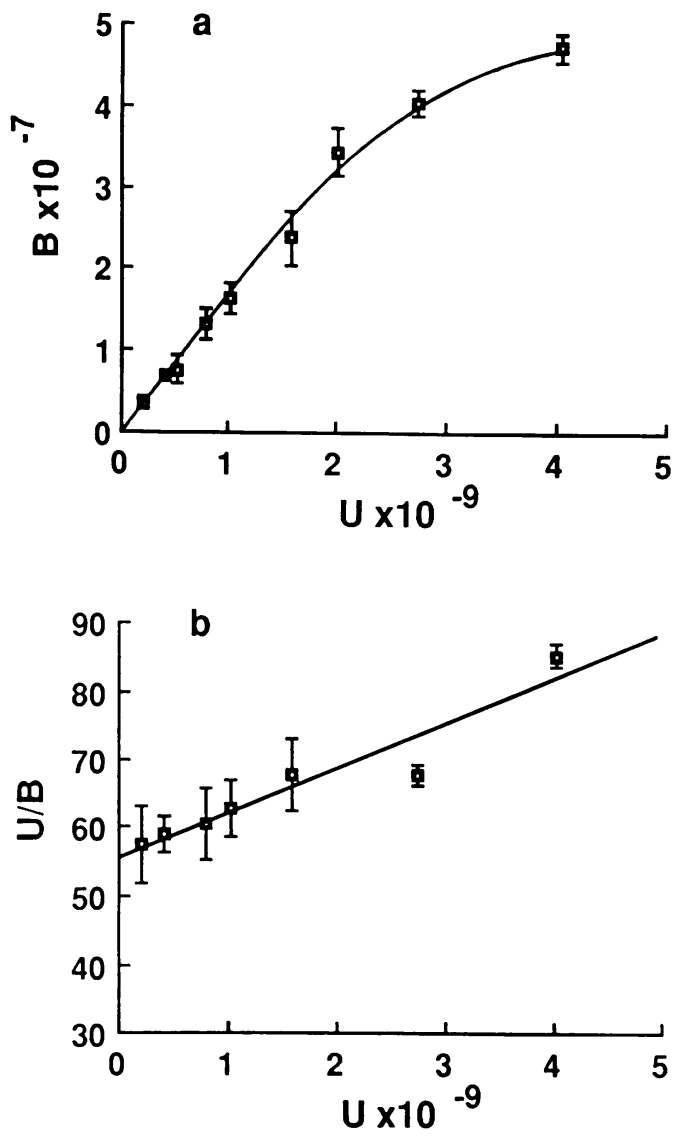

Figure 1. (a) Binding of $P$. cepacia to tracheobronchial mucin. An aliquot of $150 \mu \mathrm{l}$ of ${ }^{3} \mathrm{H}-P$. cepacia $(\mathrm{PC} 7)\left(2 \times 10^{8}-4 \times 10^{9} \mathrm{CFU} / \mathrm{ml}\right)$ was added to microtiter wells coated with tracheobronchial mucin or BSA $\left(0.52 \mu \mathrm{g}\right.$ protein/well), incubated for $1 \mathrm{~h}$ at $37^{\circ} \mathrm{C}$, and after washing four times to remove nonbound bacteria, wells were counted for bound radioactivity. Mucin binding values were corrected for nonspecific BSA binding. Each value represents the mean $( \pm$ SEM) of six independent binding experiments. $U$, unbound bacteria $(\mathrm{CFU} / \mathrm{ml}$ $\times 10^{9}$ ); $B$, bound bacteria (CFU/ $\mu \mathrm{g}$ mucin dry wt). (b) Langmuir isotherm plot of the data of Fig. $1 a$.

study period. Therefore a total of 19 out of the 22 patients produced 38 isolates which did bind to mucin, and these were segregated and grouped according to the severity of illness of the patient at the time of $P$. cepacia isolation (Table III).

$R$ values varied within each group, but the average was highest in the isolates of those patients judged to have advanced disease (group a). Six of the eight patients in group a died with severe illness within one year (three within one month) of the time the last isolate was obtained. Three of these six had $R$ values $>20.0$, while the other three had values of $11.8,5.7$, and 2.5 , respectively. There were two additional patients with advanced disease whose $R$ values are not included in Table III because none of their isolates bound to mucin. One of those patients died with severe illness, but the last isolate available from that patient was obtained 10 months before death, and we therefore do not know whether the $R$ value might have become positive had it been tested during that time. The other patient with advanced disease (but $R<2.0$ ) is still alive despite a low FEV 1 (i.e., 22\% of predicted). Despite the testing of many of his isolates, no mucin-binding activity has ever been observed. In summary, therefore, most patients with $P$. cepacia and ad-

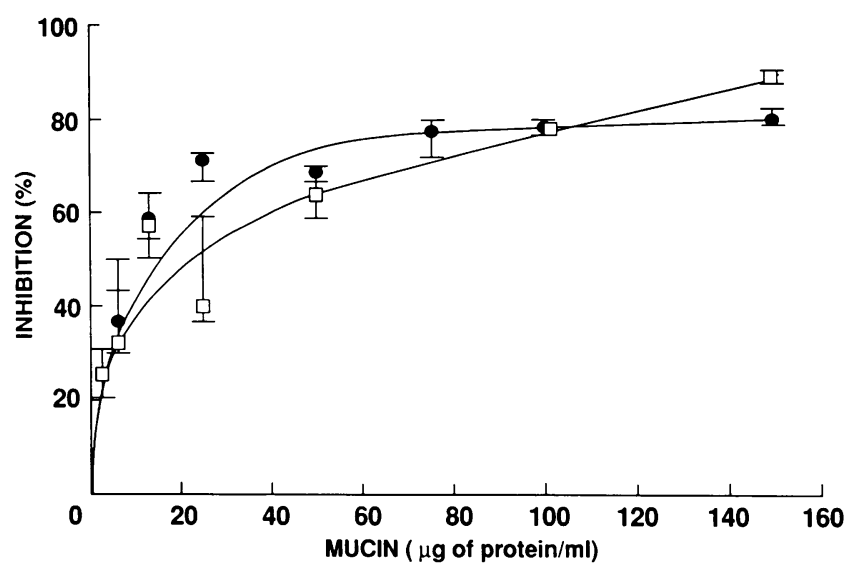

Figure 2. Inhibition of ${ }^{3} \mathrm{H}-P$. cepacia binding to immobilized intestinal mucin by preincubation with intestinal or tracheobronchial mucin. ${ }^{3} \mathrm{H}$-labelled $P$. cepacia $\left(2.55 \times 10^{8} \mathrm{CFU} / \mathrm{ml}\right)$ (isolate $\left.\mathrm{PC} 7\right)$ were preincubated with intestinal (SIM) or CF tracheobronchial mucin (TBM) $0-150 \mu \mathrm{g} / \mathrm{ml}$ for $1 \mathrm{~h}$ at $37^{\circ} \mathrm{C}$ in PBS, and then $150 \mu \mathrm{l}$ of each mixture were added to microtiter wells previously coated with intestinal mucin or BSA. Standard binding assays were performed as described in Methods and corrections made for nonspecific BSA binding. Inhibition was calculated as a percentage of control $(0 \%$ inhibition) containing no mucin in preincubation mixtures. Each value is the mean of three independent binding assays and bars represent the total range of values obtained. $\square$, TBM; $\bullet$, SIM.

vanced disease were colonized with mucin-binding organisms, but at least one patient carried a non-mucin-binding strain and is still alive, and one with a low $R$ value $(<2.0)$ died.

In six moderately ill patients (group b), the average $R$ value was lower although not statistically different from group a $(P$ $=0.077$ ). There was one death in group $b$, and it occurred within three months of the last isolate obtained. The $R$ value was 23.7 and the FEV1 was 63 , but within a very short period thereafter the clinical condition of the patient deteriorated sharply. No further isolates or FEV1 measurements were obtained during the three months before death. If we assume that this patient was incorrectly classified clinically as "moderate", and add his $R$ value to the data for group a, the difference between group a and b becomes statistically significant (i.e., $P$ $=0.024$ ). One other moderately ill patient was colonized with

Table II. Values of $N$ and $K$ for P. cepacia Binding to Mucins

\begin{tabular}{|c|c|c|c|}
\hline Isolate & Mucin & $N$ & $K$ \\
\hline & & $C F U / \mu g$ mucin & $\mathrm{ml} / \mu \mathrm{g}$ mucin \\
\hline PC 5 & SIM & $1.46( \pm 0.11) \times 10^{7}$ & $1.34( \pm 0.19) \times 10^{-9}$ \\
\hline PC 24 & SIM & $3.01( \pm 0.16) \times 10^{7}$ & $3.29( \pm 0.23) \times 10^{-10}$ \\
\hline PC 7 & SIM & $6.08( \pm 0.98) \times 10^{7}$ & $3.33( \pm 0.70) \times 10^{-10}$ \\
\hline PC 7 & TBM & $1.66( \pm 0.29) \times 10^{8}$ & $1.23( \pm 0.32) \times 10^{-10}$ \\
\hline
\end{tabular}

Langmuir isotherms were constructed from the results of binding experiments of ${ }^{3} \mathrm{H}$-labelled $P$. cepacia $\left(1 \times 10^{7}-5 \times 10^{9} \mathrm{CFU} / \mathrm{ml}\right)$ to immobilized SIM or TBM in microtiter wells. For each concentration of bacteria six binding experiments were carried out per isolate and the binding to mucin corrected for nonspecific binding to BSA. The average number of binding sites on the mucin, $N( \pm$ SEM), and the association constant, $K( \pm \mathrm{SEM})$, were derived from the intercept $\left({ }^{1} /\right.$ $K N)$ and slope $(1 / N)$, respectively. Figures in brackets represent SEM. 
Table III. Correlation of P. cepacia Binding to Mucin and Clinical Severity of Disease

\begin{tabular}{lcccc}
\hline $\begin{array}{c}\text { Severity of } \\
\text { disease }\end{array}$ & $\begin{array}{c}\text { Number of } \\
\text { positive } \\
\text { isolates }\end{array}$ & $\begin{array}{c}\text { Number of } \\
\text { patients } \\
\text { who died }\end{array}$ & $\begin{array}{c}\text { Binding } \\
\text { parameter } \\
R \pm \text { SEM }\end{array}$ & FEV1 \pm SEM \\
\hline (a) Advanced & 13 & 6 & $15.98 \pm 3.49$ & $33.6 \pm 2.19$ \\
(b) Moderate & 12 & 1 & $8.49 \pm 1.84$ & $64.7 \pm 3.27$ \\
(c) Mild & 13 & 0 & $6.85 \pm 0.82$ & $82.0 \pm 3.19$
\end{tabular}

$P$. cepacia isolates were labelled with ${ }^{3} \mathrm{H}$-acetate, concentrated to 1.2 $\times 10^{9} \mathrm{CFU} / \mathrm{ml}$; and tested for their binding to intestinal or respiratory mucins in microtiter binding assays. Specific binding to mucin, $R$ refers to a ratio of mucin binding divided by BSA binding, and was determined from three independent binding assays. Patients who died did so within the three year study period (1986 to 1989). Statistical differences were significant for comparisons of $R$ values of group a versus $\mathrm{c}(P=0.018)$, but not for a versus $\mathrm{b}(P=0.077)$ or $\mathrm{b}$ versus c $(P=0.41)$. If data from one clinically anomalous patient $(R$ $=23.7$ ) in group b (see text) are placed in group a the $P$ value for a versus $b$ would be $<0.05$. Comparisons of FEV1 values gave $P=$ $<0.001$ for a versus $b$, a versus $c$, and $b$ versus $c$.

$P$. cepacia which did not bind to mucin, and this patient remains clinically unchanged four years later.

The mild group (c) contained nine patients with isolates which bound to mucin. The average $R$ value was significantly lower than that of group a $(P=0.018)$ but not group b $(P$ $=0.41$ ). There were two other patients in the mild group whose isolates did not bind to mucin, and those patients were still alive as of December 31, 1990.

\section{Mucin receptors for $P$. cepacia}

To discover the nature of the receptor sites on mucins which are responsible for the adhesion of mucin-binding isolates, a number of experimental approaches were taken. These included the use of selected hapten inhibitors or mucins of altered composition or structure. In most experiments purified small intestinal mucin was used rather than tracheobronchial mucin due to greater availability of the former, and most experiments were performed with isolates PC 5 and/or PC 7 .

\section{Treatment with sodium metaperiodate}

Mucin and BSA-coated wells were incubated in the dark for $1 \mathrm{~h}$ at $37^{\circ} \mathrm{C}$ with increasing concentrations of $\mathrm{NaIO}_{4}$, washed four times with PBS, and the residual bound protein measured by the method of Sorenson et al. (26). No loss of bound protein ( $0.52 \mu \mathrm{g}$ protein) occurred for either BSA or mucin (not shown) as result of periodate treatment. Isolates PC 5 and PC 7 were then added and the usual binding assay performed. As shown in Table IV for SIM, periodate treatment caused a gradual decrease in PC 5 and PC 7 binding to mucin, which suggests that mucin carbohydrates are involved as receptors. No signifcance could be attached to the percentage differences between the two isolates since the concentration of bacteria added in each case was different.

\section{Treatment with carbohydrates or lectins as inhibitors}

Hapten inhibition studies were carried out by preincubating PC 5 or PC $7\left(1 \times 10^{9} \mathrm{CFU} / \mathrm{ml}\right)$ for $1 \mathrm{~h}$ at $37^{\circ} \mathrm{C}$ with individual monosaccharides which included D-fucose, D-glucose, D-galac-
Table IV. Effect of Sodium Metaperiodate on P. cepacia Binding to Intestinal Mucin

\begin{tabular}{ccc}
\hline & \multicolumn{2}{c}{ Binding (percent of control) } \\
\cline { 2 - 3 } NaIO4 & \multicolumn{1}{c}{ PC 5 } & PC 7 \\
\hline$m M$ & & 100 \\
0 & 100 & $63(59-70)$ \\
6.2 & $72(68-75)$ & $49(47-53)$ \\
12.5 & $30(20-36)$ & $41(40-46)$ \\
25.0 & $20(16-25)$ & $27(23-30)$ \\
50.0 & $5(4.1-5.7)$ & $13(12.7-13.4)$ \\
100.0 & $3(2.8-3.6)$ & \\
\hline
\end{tabular}

$\mathrm{NaIO} 4(0-100 \mathrm{mM})$ was added to mucin-coated microtiter wells and incubated for $1 \mathrm{~h}$ at $37^{\circ} \mathrm{C}$ in the dark. The wells were then washed four times with PBS-BSA. ${ }^{3} \mathrm{H}$-labelled bacteria $\left(1.34 \times 10^{9} \mathrm{CFU} / \mathrm{ml}\right.$ for PC 5 and $5 \times 10^{8} \mathrm{CFU} / \mathrm{ml}$ for PC 7) were added in triplicate to wells and binding measured as described in Methods. Similarly treated BSA-coated wells were used to correct for nonspecific binding. Control (no periodate) binding data were normalized to $100 \%$. Values represent the mean and total range of values obtained (brackets).

tose, D-mannose, $N$-acetylglucosamine, $N$-acetylgalactosamine, and $N$-acetylneuraminic acid $(20 \mathrm{mM})$. The mixture of ${ }^{3} \mathrm{H}$-bacteria and monosaccharide was then added to mucin- (or BSA-) coated wells and binding measured in the usual fashion. None of the sugars inhibited bacterial binding to mucin. Similarly there was no inhibition by the disaccharides Gal $\beta 1,3$ GalNAc, Gal $\beta$ 1,6 GlcNAc, Gal $\beta$ 1,4 GlcNAc, or GlcNAc $\beta$ $1,4 \mathrm{GlcNAc}$ used at concentrations of 2.5 and $5.2 \mathrm{mM}$ (not shown).

In separate experiments the following lectins $(5-25 \mu \mathrm{g} / \mathrm{ml})$ were individually incubated for $1 \mathrm{~h}$ at $37^{\circ} \mathrm{C}$ in mucin- (or BSA-) coated wells:helix pomatia, peanut agglutinin, Ulex Europaeus $I$, and wheat germ agglutinin. After four washes to remove nonbound lectins, ${ }^{3} \mathrm{H}-\mathrm{P}$. cepacia (PC 5 or PC 7) were added and binding assays carried out. Once again no inhibition was observed (not shown), suggesting that the simple monosaccharides or disaccharides such as GalNAc, Gal $\beta 1,3$ GalNAc, fucose, and $\beta$-linked GlcNAc, respectively, did not provide specific mucin receptor sites for the bacteria.

\section{Chloroform:methanol extracts of mucin}

Since Krivan et al. (11) have demonstrated binding of selected strains of $P$. cepacia to asialoglycolipids GM1 and GM2, we wished to confirm this finding for the isolates PC 5 and PC 7. In addition, sequential chloroform:methanol extractions of intestinal mucin $(20 \mathrm{mg})$ were performed to discover whether the mucin preparation contained any lipid contaminants capable of binding $P$. cepacia. Glycolipid standards (1-2 $\mu \mathrm{g})$ as well as $10 \mu \mathrm{l}$ of mucin extract (from a total of $100 \mu \mathrm{l}$ ) were separated by thin layer chromatography on silica gel and sprayed with Orcinol reagent. A minor band of free sugars (?) was detected near the solvent front in the mucin tract (Fig. $3 a$ ) but no recognizable glycolipid components were found. Since the sensitivity of detection was $\sim 0.5 \mu \mathrm{g}$ of glycolipid, the mucin glycolipid contamination was judged to be negligible (i.e., $<0.05 \%$ by weight). ${ }^{35} \mathrm{~S}$-labelled $P$. cepacia were overlayed onto duplicate (Orcinol-free) TLC plates, washed, and subjected to autoradiography. The mucin extract was negative, from which we con- 


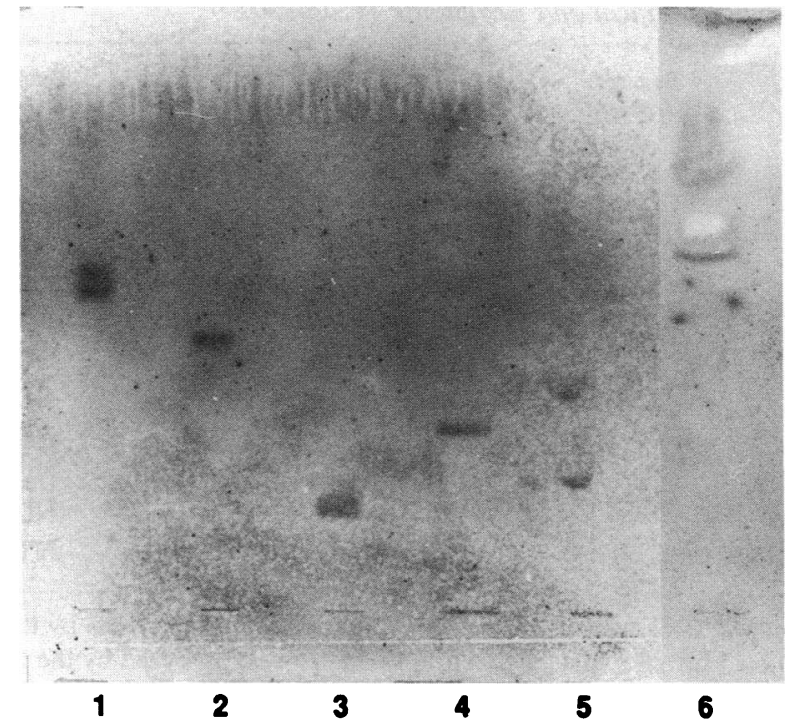

b

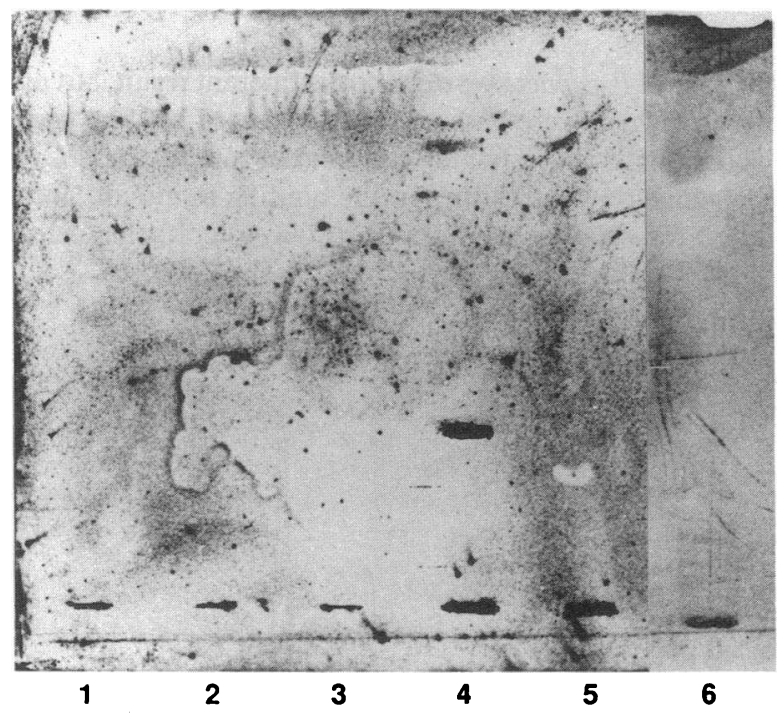

Figure 3. Thin layer chromatography of lipids and bacterial overlay with ${ }^{35} \mathrm{~S}-P$. cepacia. (a) Standard glycolipids $(1-2 \mu \mathrm{g})$ were subjected to TLC and detected by Orcinol spray 1 = lactosyl ceramide (LC), 2 $=\mathrm{Gb} 3,3=\mathrm{GM}_{1}, 4=$ asialo $\mathrm{GM}_{1}, 5=\mathrm{GM}_{2}$ and asialo $\mathrm{GM}_{2}$. Lane 6, lipid extract from $2 \mathrm{mg}$ of intestinal mucin. (b) Duplicate TLC plates were not stained but were blocked with $1 \%$ gelatin overnight at $37^{\circ} \mathrm{C}$, washed, and then overlaid with ${ }^{35} \mathrm{~S}$-labelled P. cepacia (PC 5, $2 \times 10^{9} \mathrm{CFU} / \mathrm{ml}$ ) and incubated for $1 \mathrm{~h}$ at $37^{\circ} \mathrm{C}$. After further washing to remove nonbound bacteria, TLC plates were subjected to autoradiography (5-7 d exposure to Kodak x-ray film). Bacteria bound to standard asialo $\mathrm{GM}_{1}$ (lane 4) but not to mucin lipid extract (lane 6).

cluded that our previously observed bacterial binding to mucin was unlikely to have been due to contaminating glycolipids. The only positive band was that of the asialo-GM1 standard. Asialo GM2 did not bind either PC 5 or PC 7. A consideration of the differences between the two glycolipids suggested that the receptor structure specific for PC 5 and PC 7 might be the disaccharide Gal $\beta 1,3$ GalNAC on asialo GM1. This disaccharide is also common in mucin core 1 or core 2 oligosaccharides (30). However, the previous lack of inhibition of $P$. cepacia binding to mucin by peanut agglutinin or by $\mathrm{Gal} \beta 1,3 \mathrm{GalNAc}$ disaccharide made it unlikely that core Gal $\beta 1,3$ GalNAc units of mucin were sufficient to account for the observed bacterial binding to mucin.

\section{Chemical and enzymatic treatment of mucin}

Both hapten inhibition and direct $P$. cepacia binding studies were performed on intestinal mucin samples before and after delipidation, desulfation, partial or total deglycosylation, thiol reduction and alkylation, or digestion with pronase. Compositional analyses of the mucins were carried out to monitor changes in the mucin as a result of each treatment (Table V) and to assist in the interpretation of binding results. No significant changes in amino acid profiles were noted (except for a $25 \%$ decrease in aspartic plus glutamic acid content after pronase treatment). Carbohydrate composition, however, was altered in several cases: delipidation caused an unexplained $24 \%$ decrease in fucose (21.8 to $16.6 \%)$, desulphation with methanolic $\mathrm{HCl}$ caused a major decrease in the two acid labile residues fucose $(62 \%)$ and sialic acid $(59 \%)$, as well as a loss of sulphate (98\%); TFMS (partial deglycosylation) caused a total loss of fucose, sialic acid, and galactose, as well as an $83 \%$ decrease in GlcNAc and a 57\% decrease in GalNAc. Reduction/ alkylation and pronase treatments caused no major changes in carbohydrate. TFMS plus 'reverse' $\beta$-elimination (total deglycosylation) released all of the mucin carbohydrate. The treated mucins were then used as potential hapten inhibitors in standard mucin (SIM) binding assays after preincubation with ${ }^{3} \mathrm{H}$ $P$. cepacia (PC 5) at $37^{\circ} \mathrm{C}$ for $1 \mathrm{~h}$. As shown in Table VI, totally deglycosylated mucin was not effective as a hapten inhibitor, whereas delipidated, and reduced/alkylated mucins were more effective inhibitors than untreated (control) mucin. Desulfated mucin (which was also reduced in sialic acid and fucose) was the same as untreated mucin. The most effective inhibitor was the partially deglycosylated (TFMS-treated) mucin which contained only GlcNAc and GalNAc residues. Pronase digestion gave anomalously high background binding to BSA-containing wells, which rendered mucin binding data invalid.

Some of the treated mucins were next used in direct binding experiments performed as slot-blot binding assays with ${ }^{35} \mathrm{~S}-\mathrm{la}$ belled $P$. cepacia overlay and autoradiographic detection. BSA provided a negative control. Fig. 4 was consistent with the results of Table IV in showing that binding was strongest for TFMS-treated (partially deglycosylated) mucin, moderately increased above control for delipidated mucin, and negligible for totally deglycosylated mucin. Pronase-digested mucin was the same as untreated control mucin. Desulfated mucin was not tested due to lack of material.

Taken together, both the hapten inhibition and direct binding experiments suggest that core oligosaccharide structures containing GalNAc and/or GlcNAc provided the best receptor structures for $P$. cepacia. The enhancement of binding by reducing agents and lipid extraction were judged to have been caused by conformational modifications (in either the peptide or the oligosaccharide moieties of the mucin) which "unmask" or expose the more deeply buried core carbohydrate (GlcNAc and GalNAc-containing) receptors.

\section{Use of other mucins in binding studies}

Asialo porcine submaxillary mucin, which contains core carbohydrate chains having the structures GalNAc-(ser/thr) or Gal $\beta 1,3$ GalNAc-[ser/thr] with or without $\alpha 1,2$ linked fucose 
Table V. Composition of Human Intestinal Mucin Before and After Various Chemical and Enzymatic Treatments

\begin{tabular}{|c|c|c|c|c|c|c|c|}
\hline Mol \% & No treatment & Delipidated & Desulfated & $\begin{array}{l}\text { Reduced } \\
\text { and alkylated }\end{array}$ & $\begin{array}{c}\text { Pronase } \\
\text { treated }\end{array}$ & $\begin{array}{c}\text { Partially } \\
\text { deglycosylated }\end{array}$ & $\begin{array}{c}\text { Totally } \\
\text { deglycosylated }\end{array}$ \\
\hline Asp + Glu & 12.8 & 14.7 & 12.4 & 13.6 & 9.7 & 12.1 & 13.2 \\
\hline Ser + Thr + Pro & 52.8 & 48.0 & 49.8 & 50.2 & 51.7 & 49.4 & 49.0 \\
\hline Gly + Val + Ala & 16.9 & 16.5 & 18.0 & 17.1 & 16.2 & 17.4 & 18.4 \\
\hline Ile + Leu + Phe & 11.3 & 13.3 & 12.6 & 10.0 & 13.9 & 13.3 & 11.3 \\
\hline Rest & 6.2 & 7.5 & 7.2 & 9.1 & 8.5 & 7.8 & 8.1 \\
\hline Fucose & 21.8 & 16.6 & 8.3 & 19.8 & 18.5 & ND & ND \\
\hline Galactose & 23.0 & 26.1 & 36.3 & 25.3 & 25.3 & ND & ND \\
\hline$N$-acetylglucosamine & 45.1 & 46.6 & 43.3 & 42.5 & 45.2 & 68.3 & ND \\
\hline$N$-acetylgalactosamine & 8.4 & 7.6 & 11.4 & 8.3 & 8.8 & 31.7 & ND \\
\hline Sialic acid & 1.7 & 3.1 & 0.7 & 4.1 & 2.2 & ND & ND \\
\hline Sulphate $n m o l / \mu g$ protein & 0.45 & NT & 0.007 & NT & NT & NT & NT \\
\hline
\end{tabular}

Each value represents the average of two determinations. ND means not detected. NT means not tested. Amino acids were analyzed by the Picotag system (Waters Associates, Toronto, Canada) after hydrolysis in $6 \mathrm{M} \mathrm{HCl}$ for $24 \mathrm{~h}$ at $110^{\circ} \mathrm{C}$. Carbohydrates were analyzed by the Bio LC-HPLC (Dionex Corp., Sunnyvale, CA) system after hydrolysis in $2 \mathrm{M}$ trifluoroacetic acid for $2 \mathrm{~h}$ at $0^{\circ} \mathrm{C}$. Pronase-treated samples probably contained residual pronase, therefore amino acid data may not be reliable. Sulphate was assayed by the barium-rhodizonate method of Silvestri et al. (18).

residues (27), as well as asialo ovine submaxillary mucin, which contains mainly $\alpha$-linked GalNAc as the major carbohydrate (28), were compared with normal SIM in microtiter binding studies of ${ }^{3} \mathrm{H}-P$. cepacia $\left(2.5 \times 10^{9} \mathrm{CFU} / \mathrm{ml}\right.$ of PC 5). Porcine submaxillary mucin bound $P$. cepacia only $1 / 7$ as much as SIM, and ovine submaxillary mucin did not exhibit any specific binding (not shown). These experiments suggested, by exclusion, that neither $\alpha$-linked core GalNAc- nor Gal $\beta 1,3 \mathrm{Gal}-$ NAc in mucins are sufficient to act as effective receptors. Since $O$-glycans are the dominant chains in mucin carbohydrates, the presence of GlcNAc linked to core GalNAc residues in human SIM or TBM would thus seem to be necessary for optimum binding.

The effect of mucin on $P$. cepacia binding to buccal epithelial cells

In the previous paper (15) mucins were found not to interfere with the binding of $P$. aeruginosa to buccal epithelial cells. In

Table VI. Inhibition of Binding of P. cepacia to Human Intestinal Mucin in the Presence of Treated Mucins Used as Hapten Inhibitors

\begin{tabular}{lc}
\hline \multicolumn{1}{c}{ Hapten } & Percent inhibition \\
\hline No hapten & 0 \\
Untreated mucin (control) & $28.5 \pm 2.57$ \\
Delipidated mucin & $57.9 \pm 3.75$ \\
Reduced and alkylated mucin & $57.3 \pm 6.26$ \\
Desulfated mucin & $26.6 \pm 4.20$ \\
TFMS-treated mucin & $75.3 \pm 2.60$ \\
TFMS plus reverse $\beta$-eliminated mucin & $3.3 \pm 0.68$ \\
\hline
\end{tabular}

${ }^{3} \mathrm{H}$-labelled $P$. cepacia $\left(\mathrm{PC} 5\right.$ isolate) $\left(2.65 \times 10^{9} \mathrm{CFU} / \mathrm{ml}\right)$ were preincubated with each hapten $\left(5-10 \mu \mathrm{g} /\right.$ well) for $1 \mathrm{~h}$ at $37^{\circ} \mathrm{C}$, and the mixture then added to mucin-coated wells as in standard mucin-binding assays. All values were corrected for nonspecific binding to BSA. In the absence of hapten, the $R$ value was 15.5. Each value represents the mean $( \pm S E M)$ for six independent experiments. the case of $P$. cepacia we obtained a different result, but only for isolates which were known to be capable of binding to mucin. Isolates PC 5, PC 7 (which can bind to mucin) and PC 45, PC 61 (which do not exhibit specific binding to mucin), were first tested for their ability to bind to buccal epithelial cells, (2-3

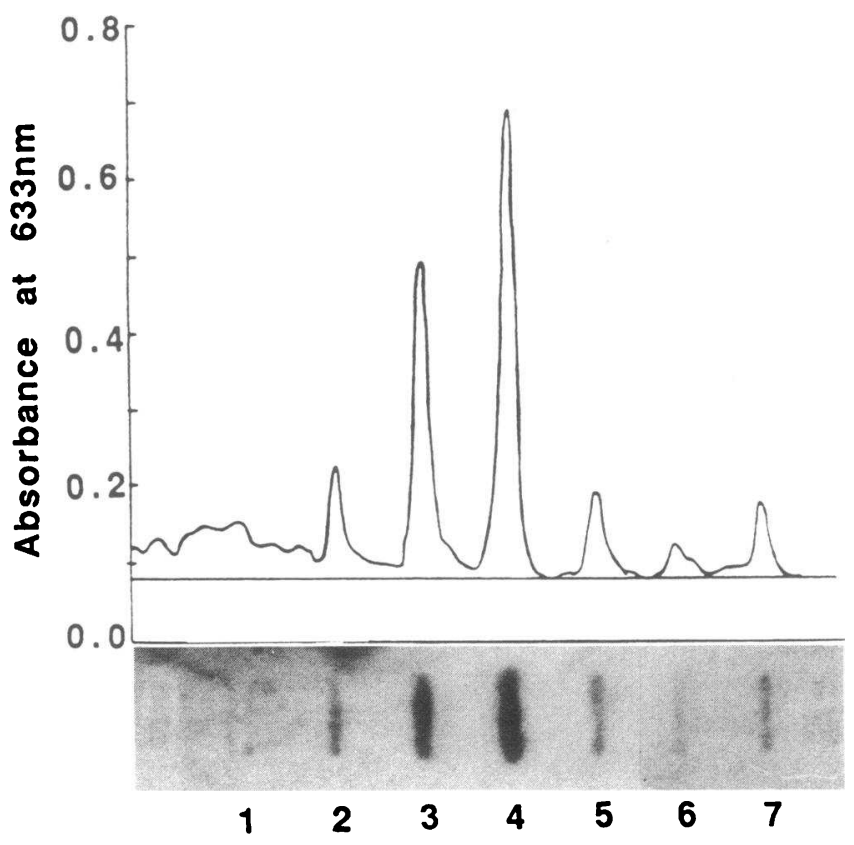

Figure 4. Slot blot direct assay of $P$. cepacia binding to chemically or enzymatically modified mucin samples. Samples containing 50,100 , and $500 \mathrm{ng}$ of mucin protein were slot-blotted onto nitrocellulose membranes, washed, and then blocked with $3 \%$ globulin-free BSA in TBS for $1 \mathrm{~h}$ at $37^{\circ} \mathrm{C}$. After further washing, samples were incubated overnight with ${ }^{35} \mathrm{~S}$-labelled $P$. cepacia $\left(\right.$ PC $\left.5,3.6 \times 10^{9} \mathrm{CFU} / \mathrm{ml}\right)$, washed six times to remove nonbound bacteria, and then subjected to fluorography. Overlays for 500-ng samples are shown on the bottom; densitometry on the top. 1, BSA (control); 2, untreated mucin (TBM); 3, chloroform:methanol-treated mucin; 4, TFMS-treated mucin, 5 , pronase-treated mucin; 6 , TFMS + reverse $\beta$-eliminated mucin; 7, untreated mucin (SIM). 
$\left.\times 10^{5} \mathrm{BEC} / \mathrm{ml}\right)$ under conditions similar to those used previously for $P$. aeruginosa $(15,24)$. All four $P C$ isolates bound in a saturable fashion, reaching values of $52,64,16$, and $36 \mathrm{CFU} /$ $\mathrm{BEC}$ at bacterial concentrations of $1.0 \times 10^{9}, 1.0 \times 10^{9}, 2 \times 10^{8}$, and $5 \times 10^{8} \mathrm{CFU} / \mathrm{ml}$ for PC 5, PC 7, PC 45, and PC 61, respectively.

At similar concentrations of bacteria and BEC, the reported binding of $P$. aeruginosa (PAK) is $\sim 181$ CFU/BEC (29), which suggests that there may be more receptor sites on BEC for $P$. aeruginosa than for $P$. cepacia.

Table VII presents the results of hapten inhibition experiments in which $P$. cepacia isolates were preincubated with different concentrations of mucin before testing their binding to BEC. Only PC 5 and PC 7 binding were inhibited significantly by mucin, and the maximum inhibition obtained was about $60 \%$. PC 45 and PC 61 (the non-mucin binding isolates) were not inhibited. All four strains therefore have adhesins capable of binding to BEC, but it is likely that these adhesins, (as well as the specific receptor sites for them on BEC), differ from the specific adhesins (and receptors) involved in mucin binding.

\section{Discussion}

Clinical isolates of $P$. cepacia obtained from the sputum of 19 out of 22 colonized patients with cystic fibrosis were observed to adhere to non-CF and CF mucins of the intestinal and respiratory tracts, respectively. There was no preference of any of the isolates tested for CF mucin versus non-CF mucin. Thus the specific receptors on mucins are essentially normal mucin components present in the respiratory and gastrointestinal tracts. The overall quantity and accessibility of mucin within the airways of patients with CF may therefore be important determinants of $P$. cepacia colonization. Isolates varied somewhat in the extent (saturation) and affinity of their adherence to mucin, which suggests that the number (and possibly the nature) of the bacterial adhesin(s) for mucins vary amongst strains.

Table VII. Effect of Mucin on P. cepacia Binding to Buccal Epithelial Cells

\begin{tabular}{|c|c|c|c|c|}
\hline \multirow[b]{2}{*}{ Mucin } & \multicolumn{4}{|c|}{ Percent binding of control } \\
\hline & PC $5^{*}$ & $\mathrm{PC} 7 *$ & PC $45^{\ddagger}$ & PC $61^{*}$ \\
\hline \multicolumn{5}{|l|}{$\mu \mathrm{g} / \mathrm{ml}$} \\
\hline 0 & 100 & 100 & 100 & 100 \\
\hline 25 & $74(72-76)$ & $68(66-70)$ & $113(104-128)$ & $104(102-107)$ \\
\hline 50 & $59(54-51)$ & $48(47-51)$ & $110(105-115)$ & $103(87-109)$ \\
\hline 100 & $58(52-66)$ & $60(53-66)$ & $113(106-119)$ & $103(98-106)$ \\
\hline 150 & ND & $52(47-56)$ & ND & $95(87-100)$ \\
\hline 200 & ND & $40(36-47)$ & ND & $87(81-98)$ \\
\hline
\end{tabular}

${ }^{3} \mathrm{H}$-labelled PC 5, PC 7, PC 45, or PC 61 $\left(2 \times 10^{8}\right.$ or $\left.1 \times 10^{9} \mathrm{CFU} / \mathrm{ml}\right)$ were preincubated with mucin $(0-200 \mu \mathrm{g} / \mathrm{ml})$ for $1 \mathrm{~h}$ at $37^{\circ} \mathrm{C}$, then added to buccal epithelial cells $\left(1.5\right.$ or $5 \times 10^{5}$ cells $\left./ \mathrm{ml}\right)$ and incubated for a further $1 \mathrm{~h}$ at $37^{\circ} \mathrm{C}$. The reaction mixture was filtered on a polycarbonate filter and the retentate counted. Binding in the absence of mucin (control) (100\%) was 23, 17, 21, and $10 \mathrm{CFU} / \mathrm{BEC}$ for PC 5, PC 7, PC 45, and PC 61, respectively. ND, not determined. * Isolates known to bind; ${ }^{*}$ isolates known not to bind specifically to mucins.
Selected strains of $P$. cepacia (particularly PC 5 and PC 7) were chosen for a more detailed examination of the binding process. In each case binding to mucin was specific (severalfold higher than to BSA controls), saturable with increasing bacterial concentration, and (for at least one isolate tested) inhibited by preincubation with mucins (SIM or TBM) before binding assays. These characteristics were not observed in earlier studies with $P$. aeruginosa, which showed no preferential binding to mucin compared to BSA (15).

Hydrophobic interactions did not participate in the receptor-mediated binding of $P$. cepacia to mucin, since tetramethylurea had no effect on binding. In contrast, $P$. aeruginosa binding to mucin (and BSA) was found to be almost completely dependent upon weak nonspecific hydrophobic interactions (15). The 'naked' peptide regions of mucin appeared to play no part in mediating $P$. cepacia attachment, since pronase digestion (which removes nonglycosylated or 'naked' areas of mucins) (21) did not reduce binding.

Several experiments suggested that specific mucin receptors for $P$. cepacia were carbohydrate in nature. Sodium metaperiodate treatment of mucin inhibited binding, as did removal of all carbohydrate by TFMS plus 'reverse' $\beta$-elimination. Although various lectins, individual monosaccharides (including GlcNAc and GalNAc) and selected disaccharides did not act as hapten inhibitors, mucin samples which were almost completely $(88 \%)$ deglycosylated were potent inhibitors. The only detectable sugars remaining on the TFMS-treated mucin were GlcNAc and GalNAc, presumably linked in the configuration of GlcNAc $\beta 1,6$ (- or $\beta 1,3)$-GalNAc (or both) (i.e., in a core 3 or partial core 4 mucin oligosaccharide configuration [30]). As shown in binding assays of PC 5 to asialo ovine submaxillary mucin and asialo porcine submaxillary mucin, the configurations GalNAc-peptide (Ser/Thr) or "Gal $\beta$ 1,3 GalNAc-peptide (Ser/Thr) were inadequate for $P$. cepacia binding. Therefore it appears to be necessary to have GlcNAc linked to GalNAc for optimum bacterial adhesion. Synthetic oligosaccharides will be used in future experiments to identify the best configurations.

Other treatments of mucin, including reduction/alkylation and chloroform/methanol extraction, were found to enhance $P$. cepacia binding, as judged by hapten inhibition and direct binding studies. Since reducing agents act to break disulfide bonds and to release the 118-kD "link" glycopeptide from native intestinal mucin, (but leave the remaining carbohydrates intact $[21,31])$ reduction probably caused unfolding and/or separation of peptide chains in a fashion that exposed underlying or normally masked carbohydrate receptors.

Chloroform:methanol extraction may also have exposed receptor sites, either by denaturing (unfolding?) mucin peptides, or by removing minor (nondetectable) lipid contaminants. Since "delipidated" mucin exhibited greater bacterial binding than intact mucin, it is highly unlikely that mucin receptors for $P$. cepacia reside on minor lipid contaminants in the mucin preparation.

The isolates of $P$. cepacia that bound to mucin were grouped according to the severity of illness of each patient at the time the isolate was obtained. Although the number of samples was small, it was interesting that isolates exhibiting the highest average mucin binding $R$ values tended to segregate with severe illness (group a), while those with the lowest average $R$ values segregated with mild illness (group c). These data do not prove, however, that a cause-effect relationship exists 
between the extent of mucin binding and progressive lung damage. It will be necessary in the future to carry out a prospective study to discover whether colonization with mucin-binding $P$. cepacia is a poor prognostic sign in patients with cystic fibrosis.

Experiments comparing the effects of mucin on $P$. cepacia binding to buccal epithelial cells suggested that those isolates that are capable of binding to mucin (i.e., PC 5 and PC 7) were inhibited (in part) from binding to BEC by added mucin, whereas those isolates (i.e., PC 45 and PC 61) with no specific affinity for mucin, were insensitive to added mucin. One might expect a priori that binding to mucin in vivo would be protective, since it would retard access of bacteria to respiratory epithelial cells and subsequent lung damage. On the other hand, within areas of stasis in the lung, secreted mucin may simply provide a reservoir for mucin-binding $P$. cepacia strains, thereby facilitating colonization. Our future efforts will be directed to isolating and characterizing the mucin-specific adhe$\sin (\mathrm{s})$ of $P$. cepacia.

\section{Acknowledgments}

Financial assistance for this work was provided by the Canadian Cystic Fibrosis Foundation. Dr. U. Sajjan was the recipient of a Canadian Cystic Fibrosis Foundation postdoctoral fellowship award. The authors are indebted to Ms. Anne Robson, Division of Microbiology, Hospital for Sick Children, for identification and provision of Pseudomonas cepacia isolates.

\section{References}

1. Ederer, G. M., and J. M. Matsen. 1972. Colonization and infection with Pseudomonas cepacia. J. Infect. Dis. 125:613-618.

2. Isles, A., I. Maclusky, M. Corey, R. Gold, C. Prober, P. Fleming, and H. Levison. 1984. Pseudomonas cepacia infection in cystic fibrosis: an emerging problem. J. Pediatr. 104:206-210.

3. Tablan, O. C., T. L. Chorba, D. V. Schidlow, J. W. White, K. A. Hardy, P. H. Gilligan, W. M. Morgan, L. A. Carson, W. J. Jason, and W. R. Jarvis. 1985. Pseudomonas cepacia colonization in patients with cystic fibrosis: risk factors and clinical outcome. J. Pediatr. 107:382-387.

4. Sobel, J. D., N. Hashman, G. Reinherz, and D. Merzbach. 1982. Nosocomial Pseudomonas cepacia infection associated with chlorohexidin contamination. Am. J. Med. 73:183-186.

5. Tablan, O. C., W. J. Martone, and C. F. Doershuk. 1987. Colonization of the respiratory tract with Pseudomonas cepacia in cystic fibrosis: risk factors and outcome. Chest. 91:527-532.

6. Thomassen, M. J., C. A. Demko, J. D. Klinger, and R. C. Stern. 1985. Pseudomonas cepacia colonization among patients with cystic fibrosis. A new opportunist. Am. Rev. Respir. Dis. 131:791-796.

7. Gessner, A. R., and J. E. Mortensen. 1990. Pathogenic factors of Pseudo monas cepacia isolates from patients with cystic fibrosis. J. Med. Microbiol. 33:115-120.

8. Lonon, M. K., D. E. Woods, and D. C. Straus. 1988. Production of lipase by clinical isolates of Pseudomonas cepacia. J. Clin. Microbiol. 26:979-984.

9. Kuehn, M., K. Lent, J. Hass, J. Hagenqieker, and A. L. Smith. 1988. Binding of Pseudomonas cepacia to respiratory cells. Pediatr. Pulmonology. (Suppl. 2):77. (Abstr.)

10. Saiman, L., G. Cacalano, and A. Prince. 1990. Pseudomonas cepacia adherence to respiratory epithelial cells is enhanced by Pseudomonas aeruginosa. Infect. Immun. 58:2578-2584.

11. Krivan, H. C., V. Ginsburg, and D. D. Roberts. 1988. Pseudomonas aeruginosa and Pseudomonas cepacia isolated from cystic fibrosis patients bind specifically to gangliotetraosyl ceramide (asialo GM1) and gangliotriosyl ceramide (asialo GM2). Arch. Biochem. Biophys. 260:493-496.

12. Baltimore, R. S., C. D. C. Christie, and G. J. W. Smith. 1989. Immunohistopathogenic localization of Pseudomonas aeruginosa in lungs from patients with cystic fibrosis. Am. Rev. Respir. Dis. 140:1650-1661.

13. Sanford, B. A., V. L. Thomas, and M. A. Ramsay. 1989. Binding of Staphylococci to mucus in vivo and in vitro. Infect. Immun. 57:3735-3742.

14. Gilardi, G. L. 1985. Pseudomonas. In Manual of Clinical Microbiology. 4th ed. E. H. Lennette, A. Balows, W. J. Hausler, Jr., and H. J. Shadomy, editors. ASM Publications, Washington, DC 350-372.

15. Sajjan, U., J. Reisman, P. Doig, R. T. Irvin, G. Forstner, and J. Forstner. 1992. Binding of nonmucoid Pseudomonas aeruginosa to normal human intestinal mucin and respiratory mucin and respiratory mucin from patients with cystic fibrosis. J. Clin. Invest. 89:657-665.

16. Slomiany, A., B. L. Slomiany, A. Witas, M. Aono, and L. J. Newman. 1983. Isolation of fatty acids covalently bound to the gastric mucus glycoprotein of normal and cystic fibrosis patients. Biochem. Biophys. Res. Commun. 113:286-293.

17. Slomiany, B. L., and A. Slomiany. Isolation and characterization of the sulfated neolactotetraosylceramide from hog gastric mucosa. J. Biol. Chem. 253:3517-3520.

18. Silvestri, L. J., R. E. Hurst, L. Simpson, and J. M. Settine. 1982. Analysis of sulfate in complex carbohydrates. Anal. Biochem. 123:303-309.

19. Edge, A. S. B., C. R. Faltynek, L. Hof, L. E. Reichart, and P. Weber. 1981. Deglycosylation of glycoproteins by trifluoromethanesulfonic acid. Anal. Biochem. 118:131-137.

20. Gerken, T. A., N. Jentoft, and R. Gupta. 1989. A new approach for chemically deglycosylating mucous glycoproteins. Glycoconjugate $J$. 6:155. (Abstr.)

21. Mantle, M., G. G. Forstner, and J. F. Forstner. 1984. Biochemical characterization of the component parts of intestinal mucin from patients with cystic fibrosis. Biochem. J. 224:345-354.

22. Laine, R. A., K. Stallner, and S. Hakomori. 1974. Isolation and characterization of membrane glycospingolipids. In Methods in Membrane Biology. 2nd ed. E. D. Korn, editor. Plenum Publishing Corp., New York. 205-244.

23. Hansson, G. C., K. A. Karlsson, G. Larson, N. Stromberg, and J. Thurin. 1985. Carbohydrate specific adhesion of bacteria to thin-layer chromatograms: a rationalized approach to the study of host cell glycolipid receptors. Anal. Biochem. 146:158-163.

24. Doig, P., T. Todd, P. A. Sastry, K. K. Lee, R. S. Hodges, W. Paranchych, and R. T. Irvin. 1988. Role of pili in the adhesion of Pseudomonas aeruginosa to human respiratory epithelial cells. Infect. Immun. 56:1641-1646.

25. Laux, D. C., E. F. McSweegan, and P. S. Cohen. 1984. Adhesion of enterotoxigenic Eschierichia coli to immobilized intestinal mucosal preparations: a model for adhesion to mucosal surface components. J. Microbiol. Methods. 2:27-39.

26. Sorenson, K., and U. Brodbeck. 1986. Assessment of coating-efficiency in ELISA plates by direct protein determination. J. Immunol. Methods. 95:291293.

27. Carlson, D. M. 1968. Structure and immunochemical properties of oligosaccharides isolated from pig submaxillary mucins. J. Biol. Chem. 243:616-626.

28. Sadler, J. E., J. L. Rearick, J. C. Paulson, and R. L. Hill. 1979. Purification to homogeneity of a $\beta$-galactosidase $\alpha 2 \rightarrow 3$ sialyltransferase and partial purification of an $\alpha-N$-acetylgalactosaminide $\alpha 2 \rightarrow 6$ sialyltransferase from porcine submaxillary glands. J. Biol. Chem. 254:4434-4443.

29. Irvin, R. T., P. Doig, P. A. Sastry, B. Heller, and W. Paranchych. 1989. Competition for bacterial receptor sites on respiratory epithelial cells by Pseudomonas aeruginosa strains of heterologous pilus type: usefulness of kinetic parameters of adherence in predicting the outcome. Microbiol. Ecol. Health Dis. 3:3947.

30. Schachter, H., and I. Brockhausen. 1991. The biosynthesis of serine (threonine)- $N$-Acetylgalactosamine-linked carbohydrate moieties. In Glycoconjugates: Composition, Structure and Function. H. Allen and E. C. Visailus, editors. Marcel Dekker, Inc., NY. In press.

31. Fahim, R. E. F., G. G. Forstner, and J. F. Forstner. 1983. Heterogeneity of rat goblet-cell mucin before and after reduction. Biochem. J. 209:117-124. 